\title{
Confucian Virtues as Moral Anchors for Business Progress
}

\author{
Chris Larsen* \\ Hankuk University of Foreign Studies, South Korea
}

*Corresponding Author: Chris Larsen, Hankuk University of Foreign Studies, South Korea

\begin{abstract}
With the so called “economic miracles" of Asia (The four tigers (亞洲四小龍): South Korea, Taiwan, Hong Kong, Singapore), Western scholars have had to reevaluate the previously common belief that models differing from western style capitalism could not bear fruit. The long-standing conception that Asian economic models are lacking and incapable of keeping pace with the economic progress of the west has recently required much reconsideration. The heat from this debate has resurrected the observations of Max Weber concerning the Protestant connection to western economic progress in determining if any similar connection exists in the socioeconomic progress of East Asia. The fact that a variety of new and successful economic systems have recently emerged on the world scene, particularly in East Asia, evidence that a certain degree of further analysis is appropriate. Management and businesses outside of Confucian states may well benefit from comparing their organization values and leadership practices and assess what values associated with the Confucian economic miracles could be adopted toward the enhancement of their own goals and missions.
\end{abstract}

Keywords: Leadership, Values, Business, Confucianism, Ethics

\section{INTRODUCTION}

The 'economic miracles' of East Asia, the tiger economies, has raised ongoing attention following four decades of dynamic growth. Japan and these 'four little tigers'- Hong Kong, Singapore, South Korea and Taiwan- grew at an incredible speed to move from relatively undeveloped, to rich and competitive in the global market, in a rather short time. This was the so called 'East Asian Miracle' by the World Bank. Thereafter, many began to turn to these states as models for successful economic development. Then hit the Asian financial crisis. Some quickly dismissed the miracles and concluded their brand of capitalism was not compatible with the modern globalizing system. Others were less certain and were not ready to end the debate concerning the development potential of the tiger economies. Decades of unprecedented economic development and transformation could not be so easily ignored. More to the point, understanding East Asia's highs and lows would allow countries as well as businesses to gain insights to improve their development models and avoid pitfalls. This paper contributes to this understanding by looking at the cultural values shared by the tiger economies.

While significant ground has been covered on global economic theory, the necessities of economic progress, and the components of such advancement, only rather recently have these discussions turned to face the cultural components of economic progress in any significant way, which are important for company's leadership to understand. This is especially timely with the recent and rapid developments now being observed in China, following the remarkable successes of the 'four little tigers'. Yet the attributes for successful development are complex, spanning economic, political, ideological, institutional and cultural origins. This paper seeks to balance and synthesize these factors to show their complement to each other as a manifestation of culture, particularly Confucian culture in this case, in the backdrop of history, economics and geopolitics. In so doing, the purpose of this paper is to illustrate the compatibility Confucian culture values toward economic progress. In particular, the significance of how the Confucian virtues found in East Asia may propagate trust and social capital, which provides an additional link toward understanding how the "economic miracles" of East Asia could seize upon the opportunities of development. This information is especially useful for business and managers who seek to model their development on the 'miracles' in a developing economy.

\section{Problem Statement and Methods}

In recent history, economic thought has been dominated by neoclassic or free market economics, a model of rational and self-interested human behavior, which although has revealed much about the 
nature of money and markets, yet doesn't cover the whole picture (Fukuyama, 1995). In so far as economics occurs between people or peoples, it is a social phenomenon, meaning that human behavior must also contribute some partial account for economic motivation. Classical economist Adam Smith, who is often famed for his discussion on supply and demand in The Wealth of Nations, understood well that economic motivations are highly complex and embedded in social customs and that humans are not just "rational utility-maximizing individuals" (ibid, p. 18) as the neoclassic economists might contend. Smith states, "How selfish soever man may be supposed, there are evidently some principles in his nature, which interest him in the fortune of others, and render their happiness necessary to him, though he derives nothing from it except the pleasure of seeing it" (Smith, 1789, p.3). Put simply, while free market economic theory is sound, reliant upon analytical factors, market trends, utility maximization, and so on, it is insufficient to fully explain the function and behavior of economies. The fact is that some nations and ethnic groups simply do better than others for reasons that transcend important factors like climate, resources, geography, size, policy decisions, or even luck. Any and all explanations should be explored, reaching beyond the confines of any particular discipline, and past the erroneous idea that discussing the progress of countries, races, ethnic groups, or any groups, is taboo: such unnecessary confines to scholarly efforts stifle progress. It is important to have a multifaceted approach to the complex problem of what encourages economic progress.

There exist numerous perspectives regarding the functioning of economies, the explanation and significance of culture, the meaning and application of Confucian doctrine, and the numerous subtle links connecting them. Recently, the discussion on the existence of these so-called links has stirred much controversy without a defined or agreed upon conceptual framework to evaluate the data. The problem is compounded, as much confusion has arisen from ambiguity and from using like terms across disciplines with varying definitions or conceptual backgrounds. This study seeks to more clearly define the links between economic progress, culture and the Confucian virtues, especially by clarifying the associated terminology, exposing links in the literature and demonstrating there is in fact a large degree of overlap between the three topics set forth by this thesis. The study is not exhaustive in scope and uses a qualitative comparative case study analysis of secondary source materials, particular those of the original Confucian texts. It also implements two frameworks for their explanatory power and assistance in conveying the connection between values and progress. The first is Fukuyama's Primacy of Culture and the second is Harrison's model of Progress-Prone and Progress-Resistant Values.

\section{BACKGROUND}

Confucianism, Neo-Confucianism, Taoism and Buddhism have been central philosophical traditions in China, and East Asia in general, for thousands of years. These traditions have strongly influenced the lives and institutions of the people and enterprises by connecting institutions, such as politics, to ethics. A major element underpinning all these systems is the concept of self-transformation and the perfection of humanity. This involves developing harmonious relationships with oneself, others and nature; however, each tradition approaches self-transformation in different ways while influencing each other over time. Confucianism is primarily concerned with human nature (jen/仁), often translated as "humanity" or "benevolence", and social virtues, while Taoism with aligning oneself with the 'Way' (Tao/道) of nature. Meanwhile, Neo-Confucianism maintains the Confucian belief structure, but adds cosmological elements from Taoism and Chinese Buddhism. This move is culturally significant because Neo-Confucianism is left with the job of reconciling the various esoteric concepts of each tradition as one coherent project. This is especially difficult because all the traditions use similar vocabulary, but often with a somewhat different nuance. Ultimately, although this move makes Neo-Confucianism very comprehensive, it also creates a tremendous amount of room for interpretation and debate regarding meaning. Therefore, Neo-Confucianism by this account, has two byproducts, 1) a very abstract and thorough account regarding the nature of life, existence, knowledge, behavior, metaphysics and so forth and 2) a very concrete and thorough account on how one should live, behave, think and function to attain self-realization and a better world. It is also the Confucianism that nearly all individuals in Confucian states adhere too. Both aspects hold a high degree of importance for culture and economics. From this, there is of course some question as to how successful and applicable Confucianism can be. Certainly, how successful Confucianism has been is subjective and vehemently endorsed by some (Tai, 1989) and flatly rejected by others (Harris, 1989). 
This writing chooses not to take sides on this argument, but rather to show compatibility, not predictability.

Although many terms will be discussed, 'harmony' functions throughout Chinese philosophy and life and should be given a special place. Developing harmony always starts with the self, and in the case of Confucianism, is usually first related to virtue and behaving virtuously (de/德). This attitude extends beyond oneself into the realm of family, society and eventually the universe (heaven/cosmos/tiān/天). The application of harmony then, to both self-cultivation and the universe, and their interdependence, means that philosophical theory and practical application cannot be separated. Furthermore, that there is no separation between the ethical and the spiritual. So, in Confucian societies, philosophers had historically wanted to hold political positions, particularly since having a high position in government also meant the possession of a developed moral character. But by holding a governmental position, scholars could more easily transform people into better individuals and hence the society into something closer to a utopia. Chinese society then naturally developed into a spiritual one, highly ordered and centered on cultivating individual, family and social harmony, which was later adopted by other countries, like Korea and Japan, which eventually implemented Confucianism to greater and lesser extents.

Confucianism holds that perfection is realized by cultivating human nature (jen/仁) and social virtues. An individual's life and associated behavior can only be perfected by developing this, what might also be called benevolence (jen/仁). According to Confucius, if everyone does this, the society will be transformed, and all will be in harmony. It is worth noting here that unlike the kinds of deconstructionist practices recently popular in the West, terms in Confucianism are multi-layered and "constructed". Human beings are reduced down to isolated biological creatures but are assumed to be embodiments of benevolence and inherently linked to the social fabric of society and all that it creates.

When Confucianism was designed, the intention was for it to be a social philosophy that would function on a political scale as well as a social scale. Generally speaking however, Confucian philosophy, irrespective of the form it takes today, tends to integrate the processes of living, meaning that it ties individuals, family, relationships, politics, society, religion, and even economics, tightly together. When one is so interconnected in one's society, it's clearer as to why principles like benevolence/altruism (jen/仁), filial piety (xiao/孝), loyalty (zhong/忠), and reciprocity (shu/恕) become increasingly important. Even one's status, whether as a philosopher or a commoner, is judged not by simple intellectual worth or power, but rather upon moral character. In this system, the goal of philosophy is to transform people into better persons; and this emphasis led naturally to emphasizing ethics and spirituality. If one's heart and mind are to be cultivated along the lines prescribed by Confucius, the prerequisite is a moral existence.

During the chaotic time Confucius lived, he concluded that the problems he saw originated from power used without moral principle, which in English might be considered immoral or evil ( $\mathrm{ak} / \mathrm{m} \mathrm{F}$ ). To fix this he urged for the regulation of the government under certain principles for the benefit of all the people. In theory, government officials would be of the highest integrity and care about the society (people) as much they did for themselves. Here we are reminded to "Do unto others as you would have them do unto you," but in a far broader sense. Confucius' concern was to know humanity, as opposed to nature. Epistemological questions did not concern him as they did later Confucian scholars, and he did not seek out the root of human integrity, happiness, or ethics, independent of people. The wisdom he is said to have compiled from the Five Classics was simply a human and principle-centered methodology to create the ideal society. The fourth book, The Book of Mencius, contributes the importance of practicing the benevolence, being noble, and honoring appropriately, in order to safeguard the integrity of humanity. Others argued these practices were to control man's inherent evil nature. Confucius didn't discuss these points directly, and regardless which is correct, Confucianism can still be called a humanistic social philosophy; about humans and social interactions, not nature or the supernatural. As such, there must be individuals who exemplify Confucius' teaching and serve as an example too all and are a beacon of moral fortitude and virtue. They are Confucian 'gentlemen,' the (chün tzu/君子), perhaps better described as 'the noble' or 'the righteous'.

In Confucianism, morally refined and righteous individuals were ideally the embodiment of Confucian virtue. For the Confucian noble, order in the universe is mirrored by moral order in human 
affairs, and in doing so all becomes harmonized. These superior individuals prize and cultivate their inner virtues beyond those of wealth or profit. This mentality is said then to move the individual beyond egoism, and if all is in harmony within oneself then actions will always be appropriate. One does not worry about being out of office but is concerned whether one has the qualities that entitle he or she for the office. One realizes that it is virtue (dé/德) that determines one's impact in a business, in a family, and on the world. "The gentleman brings out what is most admirable in people; he does not bring out what is bad in them. The petty man does the opposite." (子曰. 君子成人之美、不成人之 惡. 小人反是. The Analects 12:16) "The noble man cares about virtue; the inferior man cares about material things. The noble man seeks discipline; the inferior man seeks favors." (君子懷德、 小人懷土. 君子懷刑、小人懷惠. The Analects 4:11)

It's important to now be reminded that Confucianism is a system which has endured, in one form or another, for about 2,500 years. In that time Confucian concepts have been challenged, reformed, thrown out, revived, and beyond, for various purposes both similar and dissimilar to Confucius' original teaching. For certain discussions, it may be then appropriate to talk about "Confucianisms," rather than simply one, since a variety of prominent interpretations exist from the original Confucius to Mencius or Wang Yang Ming to Chu Hsi. That's not to mention the overt differences between Confucianism and Neoconfucianism. Fortunately, none those variations veer too far in the interpretation of the fundamental principles, which to this day continue to permeate the languages and cultures of East Asia. The fact that Confucius implied human nature was good while Mencius actually declares it to be so, doesn't change the fundamental ideas involved. While there may be epistemological or metaphysical significances, ultimately all the traditions can generally agree and be conveniently unified regarding the meaning of the fundamental principles associated with human interaction and the social virtues.

The social virtues included for this discussion as being fundamental to Confucianism, which can be linked to the development of social capital, socioeconomic process, and business development include: benevolence-Jen (仁), the 'way'-Tao (道), righteousness- $Y i$ (義), virtue- De (德), propriety /rites- $L i$ (禮), loyalty-Zhong (忠), reciprocity-Shu (恕) and filial piety-Xiao (孝). Due to the abstract and vague nature of these terms in English, a certain amount of explanation is required to accurately understanding the meaning of these terms in context and how we might apply them. It should be noted that these terms are not nearly as abstract in East Asian languages, being that a concrete understanding of each term is rooted in certain culturally specific ethical practices, behaviors and thought patterns. Although this can be somewhat true for certain terms in English, it is in general far less so.

\section{The Primacy of Culture and Trust}

For decades, understanding poverty and the disappointing levels of development seen in Latin America, Asia and Africa have boggled the minds of scholars. Even when economic or political circumstances or resource allocations are similar, there tend to be some countries that just do better than others. Francis Fukuyama's discussion of trust (Fukuyama, 1995), as a social and therefore cultural phenomenon, links the development of trust and social capital to socioeconomic development. After all, since all human interactions with one another are in some way social, those interactions are subject to all the norms and beliefs cultures provide. Human economic life must therefore come as an extension of human social behavior, not the reverse. An individual may act out of purely economic purpose, but it is all the while guided by culture. So, dimensions of culture are in this light given an increased significance because in their ability to alter social interactions, they alter economic behavior and shape economies. Trust, in particular, is especially important because it is the keystone for social capital development. The Confucian worldview provides a good illustration of this concept. The symbol for person (人) consists of two individual lines (一) places co dependently so that if one is removed, the other falls. As all existence in Confucianism is defined in terms of relationships, Confucian humanity (仁) likewise is defined in terms of relationships to other humans and the laws of the universe. The degree to which an individual, group, family, community, business, society or even country can trust, dictates the degree to which there can be predictability, reliability, stability, and security in any or all those groups. When the degree of trust is high and the radius of trust wide, social capital is proportionally so, allowing individuals to more effectively work together toward mutual benefit: a clearly important aspect for economic and business development. 
Yet opponents want qualification of such an argument and explanations for it to gain a more robust foothold since there may be other circumstantial or external causes for development to occur. Although this has been ambitiously addressed for under-developed countries, Confucian nations have not been given much thought, probably because many have been so successful. So, several further steps are taken in this paper to contextualize how social capital grows from trust in Confucian countries. The first methodological tool employed here comes from Fukuyama's "Primacy of Culture" which addresses the four levels on which the consolidation of democracy must occur: 1) Ideology, 2) Institutions, 3) Civil Society, and 4) Culture (Fukuyama, 1995, p.7-14). The significance of liberal democracy is that it appears to be the only system capable of supporting and controlling market forces, while fostering democratic virtues, in such a way to foster rapid economic development. This was thoroughly discussed in Fukuyama's earlier work The End of History and the Last Man. The interesting and important concern may then be raised as to whether Confucianism and liberal democracy stand in opposition, but for the purposes of this paper it is irrelevant, because concerns about better systems, and what defines "better" are not addressed here. The question is whether the key Confucian virtues are compatible with trust and social capital creation, which fosters economic development. To such ends, it is clear that Confucian society can also be contextualized by these four levels and interpreted the same as with liberal democracy.

\subsection{Level 1: Ideology}

A society may take shape in any number of ways, but for it to have any lasting power the society must establish legitimacy, and this holds especially true for democracies and Confucian States alike. The level of ideology is the level where normative beliefs about the rightness or wrongness of a system are rooted. In terms of development-oriented societies, the individuals of the society must believe in the legitimacy of the system for progress to occur. In Confucian states, or even businesses, legitimacy should come from the embodiment of virtue (德) and humanism (仁), as well as the other Confucian virtues, otherwise it will lose its mandate and the people would be morally obligated to move against the corrupt entity. Yet perceptions and ideology can change rapidly so level 1 is also considered the most flexible level, progressing toward the more inflexible, like level two, that of institutions.

\subsection{Level 2: Institutions}

Ideology alone cannot sustain a complex organization without the use of support structures, the institutions. Legal systems, constitutions, political parties, and economic structures are all examples of institutions that reinforce the principles of the ideology in a state. In the Confucian case, the Four Great Books Analects, Great Learning, Doctrine of the Mean and Book of Mencius offer guidance in the forming of intuitions, but fundamentally it is understanding the Confucian Virtues that unlocks how to form true Confucian institutions. Generally, institutions are formed and manipulated by public policy and change less quickly since legitimacy has already been established. Political struggles occur in this level as well, which is also one area where Confucianism has always had great difficulty. Confucius spent most of his life trying to rectify society, particularly at the level of institutions, since ideally if the leadership was virtuous, so too would the populous follow by example. Unfortunately, during his life he had little success in this regard. The later politically inspired propagation of Confucianism would be the juggernaut to change the Chinese culture from that time forward.

\subsection{Level 3: Civil Society}

What Fukuyama calls "spontaneous socialization" is a very important aspect of trust, social capital and economic development, and it underpins the third level: Civil Society. Put simply, when individuals come out and participate in society they bring with them a level of trust or distrust that fosters or hinders social development and social capital. When levels of trust are high, individuals more readily form groups and complex social networks for reciprocal gain. These social ties often underlie the political institutions for ideological reasons, but also because as policy effects society, the opposite is also true. Interestingly, Confucian states have long been very strong in the arena of forming social networks, and sometimes to the detriment of the larger society, but typically the ability to form civic institutions fosters trust and therefore social capital, which enhances development. However, at the core of "spontaneous socialization" is a value that fosters trust, allowing level three to flourish, or wither it its absence. Without the culture foundations for trust and social capital development, the higher levels don't have a strong enough root to sustain themselves. Confucianism as a social philosophy is by far strongest in this area, level 4, allowing for a propensity for spontaneous socialization and the development of civil society, which is often seen in East Asia. 


\subsection{Level 4: Culture}

The deepest and most inflexible level of a society is culture. Culture is many things, but for the purpose of this discussion culture is essentially the a-rational ethical habit about what is valued, often from tradition, and from this crystallizes the phenomena of family, ethics, morals, religion, rules of behavior, and so on (Fukuyama, 1995). It is both slow changing and hard to change because its influence is so penetrating, even to the vernacular of language. To do so essentially require long-term adaptive changes to occur in the above three levels, typically starting at the level of policy, in order to nudge culture onto a different course. Confucian legitimacy came by way of history and a desire to resurrect the utopia of the past, but later as partly a means of control, Confucian texts became required study around which all of Chinese society was to center. Generations after generations of Chinese lived and breathed Confucian doctrine and its virtues became infused in the fabric of culture, and soon after all four levels became enmeshed in Confucianism. To be Chinese was indistinguishable from being Confucian. All countries that had any lasting historical relationship with China (not obstructed by extreme distance) could not avoid being, to some extent, Confucian at the core. Today, mainland China including Hong Kong, Taiwan, Singapore, North and South Korea and Japan are all to a greater or lesser extent culturally Confucian, despite contradictory practices at levels 1 and 2 in some cases. In those cases, without much surprise, their totalitarian nature has little acceptance by the people, fostering a low radius of trust and little "spontaneous socialization", which ends in poor socioeconomic development. Meanwhile, in considering Japan a unique and separate case, Hong Kong, Singapore, South Korea, and Taiwan, all with Confucian underpinnings, have experience unprecedented growth and development.

\section{Harrison: Typology of Progress-Prone and Progress Resistant Cultures}

The critically acclaimed book Underdevelopment is a State of Mind: The Latin American Case (1985) challenged the politically incorrect notions of cultural relativism, particularly in terms of development. Simply stated, development involves more than just opportunity or resources. The cultural preconditions for levels 3, 2, and 1 must be established first. Twenty years later arose the "Culture Matters Research Project" (which developed the ideas much further, into in-depth qualitative research into the social elements that contribute to progress and those that hinder it). Although "idealized", the Typology fits tightly into the ideals associated with Confucian societies. The research spans 25 elements of culture with data from the World Values Survey over 20 years and thoroughly scrutinized by researchers and scholars (Harrison, 2006, p.36-55). The 25 factors include Worldview (Religion, Destiny, Time Orientation, Wealth, Knowledge), Values (Ethical Code, "The Lesser Virtues", Education), Economic Behavior (Work/Achievement, Frugality/Prosperity, Entrepreneurship, Risk Propensity, Competition, Innovation, Advancement), and Social Behavior (Rule of Law/Corruption, Radius of identification and trust, Family, Social Capital, Individual/Group Emphasis, Authority, Role of Elites, Church-State relations, Gender relationships, and Fertility.

Similarly, as with table one, a comprehensive comparative analysis of how much overlap exists between the centrally important values of Confucianism (Level 1), and those of progress-prone societies, will demonstrate the degree to which Confucian Virtues foster socioeconomic development, or hinder it.

\section{RESUlts/Discussion}

Harrison's research focus was to enhance the qualitative aspect of how values could encourage or deter progress in a society. The research of this paper applies that model to the Confucian values. Since the discussions have touched upon culture, economic factors, Confucian values and the individual virtues, the next step is to see how these virtues may fit into Harrison's research and overall whether these virtues have the aspects that make them "Progress-Prone" or "Progress Resistant". The economic and cultural aspect of each virtue was reviewed against Figures 1 to determine if the virtue was "prone" or "resistant" and illustrate the overlap of values. Figure 1 identifies which aspects of the figure have a high degree of association and that the Confucian Virtue indicated can foster that development based on the definition provided by Harrison. For example, if the category is Religion, then "Progress-Prone: Nurtures rationality, achievement; promotes material pursuits; focus on focus on this world; pragmatism. Meanwhile, Progress-Resistant.: Nurtures irrationality; inhibits material pursuits; the other world; utopianism. Of the ten Confucian virtues studied, if 6-10 of the Confucian values discusses have an aspect that reinforces either column, "yes" was marked. Fewer than 3, "no" 
and in between as "partially". Several may also include the "yes and yes" possibility. This means that certain values are in some ways Progress-Prone and in other ways Progress-Resistant, or that 6+ values can differ and apply to both categories. For example, again in the case of "religion" while Confucianism has the progress-prone aspects of: focus on this world, pragmatism, achievement orientation and rationality, it is likewise process-resistant in its nurturing certain irrationalities and nativities, focusing on the Tao and the outer world, as well as being fixed on utopianism and idealism. Hence whether being "prone" or "resistant" would depend largely on the circumstances and which of the virtues are in use in a certain situation.

Figure1. Progress-Prone and Progress-Resistant assessment of Confucian Values

\begin{tabular}{|c|c|c|c|}
\hline & & $\begin{array}{c}\text { Confucian Virtue Compatible } \\
\text { with Progress-Prone Cultural } \\
\text { Values }\end{array}$ & $\begin{array}{c}\text { Confucian Virtue Compatible } \\
\text { with Progress-Prone Cultural } \\
\text { Values }\end{array}$ \\
\hline & Worldview & & \\
\hline 1 & Religion & Yes & Yes \\
\hline 2 & Destiny & Yes & No \\
\hline 3 & Time Orientation & Yes & No \\
\hline 4 & Wealth & Yes & No \\
\hline \multirow[t]{2}{*}{5} & Knowledge & Yes & Yes \\
\hline & Values, Virtues, & & \\
\hline 6 & Ethical Code & Yes & No \\
\hline 7 & The lesser virtues & Yes & No \\
\hline \multirow[t]{2}{*}{8} & Education & Partially & Partially \\
\hline & Economic Behavior & & \\
\hline 9 & Work/achievement & Yes & Yes \\
\hline 10 & Frugality and prosperity & Yes & No \\
\hline 11 & Entrepreneurship & Partially & Partially \\
\hline 12 & Risk Propensity & No & Yes \\
\hline 13 & Competition & Yes & Partially \\
\hline 14 & Innovation & Partially & Yes \\
\hline \multirow[t]{2}{*}{15} & Advancement & Yes & Yes \\
\hline & Social Behavior & & \\
\hline 16 & Rule of Law/Corruption & Yes & Yes \\
\hline 17 & Radius of identification and trust & Yes & Yes \\
\hline 18 & Family & Yes & Partially \\
\hline 19 & Association (social capital) & Yes & No \\
\hline 20 & The individual/the group & Yes & Yes \\
\hline 21 & Authority & Partially & No \\
\hline 22 & Role of elites & Yes & No \\
\hline 23 & Church-state relations & No & Yes \\
\hline 24 & Gender relationships & Partially & Yes \\
\hline 25 & Fertility & Yes & No \\
\hline
\end{tabular}

The next section discussed each of the values and what Progress categories they fit into based on the definitions provided by Harrison. While the chart above can help an organization determine if their outlook is progress-prone or resistant at a cultural level, the values below pinpoints the specific values that can contribute to progress. Both these categories of information can be applied to organizations and management strategies to determine their degree of proneness or resistance to progress in an organization, corporation, or country.

Benevolence: Jen (仁) Progress Prone in: religion, destiny, knowledge, ethical code, advancement, rule of law, radius of trust, family, social capital, the individual/group, authority, role of elites, gender relationships and fertility. Process-Resistant in: partially in gender relationships.

"Do not do to others what you would not like them to do to you." (Analects 15:23)

"To feel much for others and little for ourselves; to restrain our selfishness and exercise our benevolent affections, constitute the perfection of human nature" (Adam Smith, 1749)

Jen as benevolence may be viewed as the love of humanity or the ultimate (moral) principle of human action. Worth in life is drawn from jen and to live according to jen requires the development 
conscientiousness (忠/Zhong) and the extension of it to others (恕/shu: altruism). Being truly human means being endowed with 'moral character,' 'love,' and 'human goodness,' which are of emotion; here the emphasis is on the heart (心), instead of logic, as the cornerstone human nature. The character itself (仁/jen) combines 'two' (二) 'people' (人) together, bringing together the concepts of self and other, into one. Humanity, therefore, means human social interaction and codependence. It is that which makes man a moral being. The superior man, the Confucian noble (君子), never abandons this morality, including in the face of death. "To master oneself and return to propriety (禮) is humanity." "If the ruler can for one day master himself and return to propriety, all under heaven will return to humanity." (Analects 12:1) This character is contrasted with 個/gè , "individual," the combination of person (人) and "enclosed" (固): someone who is cut off or isolated from others. Jen (仁) is therefore the supreme virtue representing human qualities like loyalty (忠) and altruism (恕) when functioning at their best. What you don't want for yourself, you don't want for others, because of jen.

Propriety/Rites: $L i$ (禮) Progress Prone in: religion, destiny, time orientation, wealth, knowledge, ethical code, advancement, rule of law, radius of trust, family, social capital, the individual/group, partially in authority, role of elites, gender relationships and fertility. Process-Resistant in: religion, partially in Gender Relationships, Partially in Authority, Partially in Risk Propensity, Partially in Education.

To actualize jen, rules for everyday behavior are necessary. Confucius outlined the principle behind such a set of rules with $l i$ (禮 propriety/rites). $L i$ (禮) was long before understood as the governor of custom, ceremony, and relationships in human life through which jen could be realized. The conduct then is simply the appropriate action to harmonize with jen, and so any action that isn't in accord with $j e n$, is not $l i$. These behaviors become the means by which to control and refine human impulses into being civilized and truly human. This ultimately can be defined as the moral discipline in personal conduct, for social order, for ritual and for ceremony. It is clearly defined as well, determining the nature and behavior of social relationships, especially in regards to the five cardinal relationships. If one considers jen as the root of humanity within people, we can consider $l i$ as the fertile soil that feeds the root towards growth and blossoming. $L i$ has a origin in putting things in order, so it attends to the underlying system that organizes, which is certainly an important aspect of business and management.

Filial Piety: Xiao/Hsiao (孝) Progress Prone in: Time Orientation, Knowledge, Ethical Code, Advancement, Rule of Law, Radius of Trust, Family, Social Capital, the Individual/group, Authority, Role of Elites, Gender relationships and Fertility. Process-Resistant in: Gender Relationships, Authority, Risk Propensity, Partially in Education.

Family may be considered the most fundamental unit of society and as providing the basis for socialization. Children develop love and respect for their parents, brothers, sisters, and relatives. This becomes the foundation for extending love and respect to all hu manity. However, xiao (孝) is not just for family; it grows from the basic social unit of family into viewing the larger society as one's family as well. If individuals can respect and love all humanity, the only thing remaining is the cultivation of jen. So, the earliest stages of jen are found in xiao. Of course, there is a less abstract significance in xiao in that parents should be honored because one receives life from them. To show respect for that gift, one should also take care of one's heath. Doing well, being successful and cultivating respect is also a logical extension of this concept. Xiao encompasses all degrees of care and respect, from the physical to the emotional and spiritual, which after the parent's death would include fulfilling their wills and performing ancestral ceremonies. All this is the correct and proper expression of love for one's parents, which forms the basis for a love for humanity.

Righteousness/Rightness: $Y i$ (義) Progress Prone in: Religion, Destiny, Time Orientation, Wealth, Knowledge, Ethical Code, the Lesser Virtues, Advancement, Education, Achievement, Frugality/Prosperity, Rule of Law, Entrepreneurship, Radius of Trust, Family, Social Capital, the Individual/group, Authority, Role of Elites, Gender relationships and Fertility. Process-Resistant in: Possible in Competition

$Y i$ consists of not only knowing what is right, but also in doing what is right. This is the task of the upright individual whose character has been cultivated. How one acts when alone, for example. Would it be morally right ( $y i)$ to take advantage of a situation unfairly for personal gain? Those with 
$y i$ would say 'no'. Risking one's life for the moral right is unquestioned and clearly understood by the cultivated individual. Individuals who act in accordance with $y i$, because it is simply correct to do, are close to jen. Living with a love and respect for humanity (jen), because it is right, for that reason alone, are acting with $(y i)$. So, this is then also associated with 天理/tien li, the sense of shame and distaste. For the noble, (yi/義) is regarded as the materiality of everything. S/He exercises honor with propriety (禮/ $L i$ ). S/He demonstrates rightness in acting with humility, and by being faithful to principles until finished. To consider that the morally right path doesn't exist, is simply illogical to the cultivated, meaning that the person under inspection cannot understand the obvious. To not do what is right, means the individual is uncultivated.

The Way: Tao/Dao (道) Progress Prone in: Religion, Destiny, Wealth, Knowledge, Advancement, Ethical Code, Rule of Law, Radius of Trust, Family, Social Capital, the Individual/group. ProcessResistant in: Religion, Knowledge, Education.

Tao has become a relatively well known, although an often-misunderstood term that has generally gained popularity in the West with the spread of Taoism. The Confucian tao, although similar, is notably different. The tao is not mysterious, although it may be intangible and abstract. Like gravity, which influences matter and energy, it obviously acts upon things, but is yet unknown as to how it works exactly. Similarly, the tao underlies all things in the universe, prescribing form and manifestation for everything from gravity to individuals. It is found at the deepest part of one's being. For Confucianism, the human tao (人道) is truth, and is born out of the divine tao (天道), also truth. The divine tao is seen manifest in all things by their existence, and in humans it is what makes man respectable and precious. Cultivating oneself, a manifestation of the tao, then requires looking within to understand the tao, and so, the nature of all things. For Confucianism, unlike Taoism, obtaining a mystical union with the tao is considered somewhat inhuman because humans are social creatures and imbued with a unique character compared to all other things between heaven and earth. It is rather valuable then to cultivate social virtues to illuminate the tao; to learn how to be a good person, an honored son, an exceptional father, a favored brother, a great friend, and a valuable citizen, which will then foster an ethical social order. Where Buddhism seeks unattachment to relieve suffering, Confucianism seeks out attachment and the cultivation of human relationships.

Loyalty/Conscientiousness: Zhong (忠) Progress Prone in: Time Orientation, Wealth, Knowledge, Ethical Code, Advancement, Rule of Law, Radius of Trust, Family, Social Capital, the Individual /group, Authority, Role of Elites, Gender relationships and Fertility. Process-Resistant in: None

Zhong is the full development of one's mind and character. The character consists of 中 "center" and 心 "heart/mind." This may convey the idea of "that which should at the center/core of one's heart," namely "loyalty." Some scholars suggest 中 is used purely phonetically to express "void," to convey the idea of "making one's heart a void," or to "become selfless." This would lead by extension to concerning oneself only with others and hence the meaning of "devotion/loyalty." The concept clearly manifests itself in all other Confucian principles, for if a society is to reach a state of harmony, individuals must consider one another and be conscientiousness within all aspects of society be they family or the public.

Reverence/Mindfulness. Kyŏng (敬) Progress Prone in: Wealth, Knowledge, Ethical Code, Education, the Lesser Virtues, Advancement, Rule of Law, Radius of Trust, Family, Religion,Social Capital, the Individual/group, Partially in Authority, Role of Elites, Gender relationships and Fertility.

\section{Process-Resistant in: Authority, Competition, Propensity}

Kyŏng is "reverence". Whenever someone is devout or pious, it requires mindfulness. It could be attention to one's inner state, or to external circumstances. Everyone has as inner life of thoughts and emotions and kyŏng is in essence developing the practice of being attentive to what is within one's mind, as well as without in the surrounding environment. The result is carrying oneself properly, with an upright demeanor, including how one "stands" or presents his or herself to the world. Kyong is the anthises of slavishness, which empowers things to have control over one's mind or body. Kyong does not endure a wandering mind or body, but seeks focus and stillness, even when moving. It isn't that kyŏng is serious, for there is a time for being jovial and playful, but it is not flippant and inattentive. Reverence then implies one is an active participant, ever present, not feckless and inconsiderate. 
Altruism: Shu (怒) Progress Prone in: Religion, Destiny, Ethical Code, Radius of Trust, Family, Social Capital, the Individual/group, Gender relationships and Fertility, Partially in Innovation. Process-Resistant in: Competition

Shu concerns the extension of one's mind to others. The character is composed of 如 "to speak" with 女 “womanly," together meaning the skill of recognizing the circumstances and the disposition others, further combined with 心 "heart/mind," which adds the heartfelt, genuine and emotional component. The combination portrays the idea of acting in accordance with the higher impulses of one's nature. Forgiveness and the general concern for the well-being of others and one's position in relation to them are major elements of shu. Altruistic behavior can be considered the representative virtue found in individuals whose society has well developed radius of trust and social capital. The free ability to help others and gain personal satisfaction in the process, irrespective of material gain, is a strong indicator of a well-developed society, and economy, since those virtues also reinforce development.

Nature, disposition: Sheng (性) Progress Prone in: Religion, Destiny, Knowledge, Ethical Code, Rule of Law, Radius of Trust, Family, Social Capital, the Individual/group, Authority, Role of Elites, Gender relationships and Fertility. Process-Resistant in: None

Sheng (性) is one's "nature" or "disposition," the divine way as received in a person (人性), the highest thing in man, the source of all beauty, truth, goodness, and value in man. It is the basis for the moral judgment of good and evil. While the question of whether sheng is innate may be interesting, it's more important to note that it contains within it the potential for humanity and compassion, which are developed or intentionally shaped through learning and culture. With education, discipline, and attention to "good" things, one's natural empathy and charity can grow and become part of a perfected ethical mindset (jen/仁). Learning and education are important here since nature does not give us all the tools refine ourselves wisely. Therefore, through the study of humanity and what the meaning of virtue, people can raise their level of conscious awareness as well as the direction of their moral compass.

\section{Virtue: De (德) Progress Prone in: All Process-Resistant in: None}

$D e$ is the potential built into one's nature, one's virtue as something received (得) from heaven through which man comes to know heaven. $D e$ is the locus within oneself where the person and heaven meet, and like heaven, it manifests the pure and simple desire to give. When each person makes his/her $d e$ (德) shine (明德), peace and harmony will come to the world. The "brightening" of 德 is the action of coming to know the self, and in doing so, heaven. In social practice virtue is manifest in (德性) “moral character" or a “civilizing influence" meaning one's virtuousness inspires others to follow the moral path." De (德) is socially the power of moral example. It is the power of the sage. It encourages one to focus on oneself toward the betterment of oneself and others, to be selfmotivated, creative, and refined in thought and action, and encourage development of the society.

\section{CONCLuSion}

It is common sense that businesses and managers should be strive to be good, and to be virtuous, but these ideas are often subjective and left up to the individual to decide, so the end result is mixed and inconsistent. This article has continued a conversation regarding how to make mangers and businesses clear and consistent in their values, and have those values also be consistent with socioeconomic progress and business development. The case being made here is that Confucian values are consistent with socioeconomic progress and development, which helps explain the success that has been unfolding in East Asia in recent decades. Among those groups of people, their development story has Confucianism at the bottom (level 1), which means that since Confucian values are part of their culture and worldview, there is a corresponding degree of Confucian influence on the other levels necessary for development: civil society (2), institutions (3), and ideology (4). While other countries and businesses cannot change their cultures to be Confucian, they can still take an active approach to looking at the explicit and implicit values associated with trust in their organizations (civil society), goals in their institutions, and principles of their ideology or Mission Statement. If progress-resistant values are discovered, they can then be removed and replacing with progress-prone values. This study has analyzed some key progress-prone values from Confucianism that can be used in any or policy to help foster a greater shift toward positive growth and development in that organization. 


\section{REFERENCES}

[1] Confucius. The Analects of Confucius: A Philosophical Translation. New York: Ballantine Books, 1999.

[2] Confucius. The Analects of Confucius. New York. Colombia University Press, 2007.

[3] Confucius. The Analects of Confucius. http://www.acmuller.net/con-dao/analects.html\#div-5 (accessed April 10, 2019).

[4] Confucius. The Great Learning. http://classics.mit.edu/Confucius/learning.html (accessed April 10, 2019).

[5] Engholm, Christopher. When Business East Meets Business West: The Guide to Practice and Protocol in the Pacific Rim, John Wiley \& Sons, New York, (1991).

[6] Fukuyama, Francis. Primacy of Culture. Journal of Democracy 6(1) 7-14, (1995)

[7] Fukuyama, Francis. Trust: The Social Virtues and the Creation of Prosperity. The Free Press, (1995).

[8] Harrison, Lawrence. Culture Matters: How Values Shape Human Progress. New York, N.Y: Basic Books, (2001).

[9] Harrison, Lawrence. The Pan-American Dream- Do Latin America's Cultural Values Discourage True Partnership with the United States and Canada, Basic books, (1997).

[10] Harrison, Lawrence E. Underdevelopment Is a State of Mind, University Press of America, (1985).

[11] Harrison, Lawrence. (2006). "The Central Liberal Truth: How Politics Can Change a Culture and Save it From Itself'. Pg 36-55.

[12] Legge, J. Confucian Aknalects, The Great Learning and The Doctrine of the Mean. New York: Dover Publications, 1971.

[13] Myrdal, Gunnar. Asian Drama: An Inquiry into the Poverty of Nations, The Twentieth Century Fund, (1968).

[14] Pye, Lucian W. The New Asian Capitalism: A Political Portrait, in Peter L. Berger and Hsin-Huang Michael Hsiao (eds. ): In Search of an East Asian Development Model, Transaction Books, (1988).

[15] Romar, Edward. Globalization, Ethics, and Opportunism: A Confucian View of Business and Relationships. Business Ethics Quarterly, 14(4), (2004).

[16] Smith, Adam. The Theory of Moral Sentiments. (1749).

[17] Weber, Max. The Protestant Ethic and the Spirit of Capitalism (Translated by Talcott Parsons), Charles Scribner's Sons, (1958).

\section{AUTHORS' BIOGRAPHY}

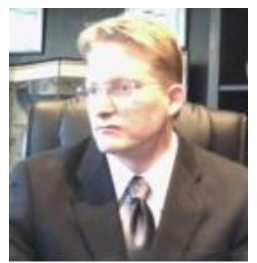

Chris Larsen teaches coursework in comparative culture, international relations, and business, at the Hankuk University of Foreign Studies in Seoul, South Korea. Dr. Larsen is an area expert on Korean culture and language with nearly twenty years teaching, writing, and presenting experience in the field. Inquiries can be directed to larsenprof@gmail.com

Citation: Chris Larsen. “ Confucian Virtues as Moral Anchors for Business Progress" International Journal of Managerial Studies and Research (IJMSR), vol 7, no. 4, 2019, pp. 101-111. doi: http://dx.doi.org/ 10.20431/2349-0349.0704001.

Copyright: (ㅇ 2019 Authors. This is an open-access article distributed under the terms of the Creative Commons Attribution License, which permits unrestricted use, distribution, and reproduction in any medium, provided the original author and source are credited. 